\title{
TITLE: Successful treatment of refractory folliculitis decalvans with secukinumab
}

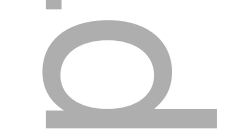

RUNNING TITLE: Secukinumab in folliculitis decalvans

(

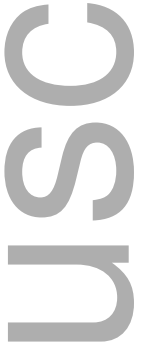

AUTHORS:

Fathima Ferial Ismail (Corresponding Author)

MBBS, BMedSci

Clinical trials Sub-Investigator and Dermatology Research Fellow

Sinclair Dermatology, 2 Wellington Parade, East Melbourne, Victoria 3002, Australia

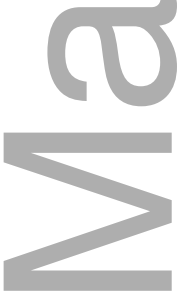

f.ferial.ismail@gmail.com

0431345524

ORCID number: 0000-0002-9515-7996

Rodney Sinclair

MBBS, MD, FACD

Sinclair Dermatology, 2 Wellington Parade, East Melbourne, Victoria 3002, Australia

Professor of Dermatology, University of Melbourne, Australia

Director Dermatology, Epworth Healthcare, Victoria, Australia

KEY WORDS: folliculitis decalvans, scarring alopecia, alopecia, secukinumab, interleukin$17 \mathrm{~A}$

CONFLICTS OF INTEREST: RS has served as an investigator in clinical trials sponsored by Novartis.

This is the author manuscript accepted for publication and has undergone full peer review but has not been through the copyediting, typesetting, pagination and proofreading process, which may lead to differences between this version and the Version of Record. Please cite this article as doi: $10.1111 /$ AJD.13190

This article is protected by copyright. All rights reserved 
ACNKOWLEDGEMENTS: We would like to acknowledge Novartis Pharmaceuticals for compassionate supply of secukinumab.

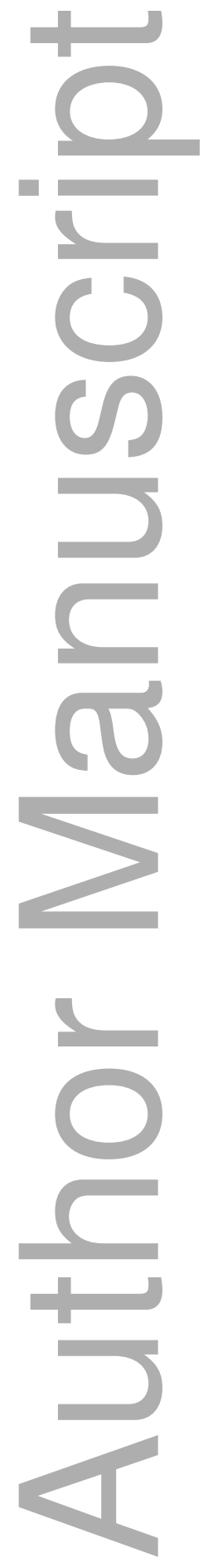


DR. FATHIMA FERIAL ISMAIL (Orcid ID : 0000-0002-9515-7996)

PROF. RODNEY SINCLAIR (Orcid ID : 0000-0001-6751-1428)

\section{- \\ Article type : Case Letter \\ ( \\ TITLE: Successful treatment of refractory folliculitis decalvans with secukinumab \\ WORD COUNT: 470 words}

\section{MANUSCRIPT:}

A 30-year-old lady presented to our clinic with a 14-year history of folliculitis decalvans. She had no significant past medical history. She first developed the condition at the age of 15 years with a small patch of hair loss on the vertex of the scalp which gradually enlarged. She had previously had an anaphylactic reaction to intralesional triamcinolone. Other treatments which had been trialled with minimal improvement included topical corticosteroids, several oral antibiotics including rifampicin, fucidin and doxycycline and a 2-month course of isotretinoin. Examination revealed a large oval patch of hair loss with erythema, scaling and crusting.

Cyclosporin 10mg daily was commenced and over a 12-month period the dose was slowly increased to $100 \mathrm{mg}$ twice daily. Concurrent treatments included laser hair removal therapy, minocycline $50 \mathrm{mg}$ daily, topical clobetasol dipropionate $0.05 \%$ and an antiseptic shampoo. After 9 months, there was no improvement in her condition and she elected to undergo a central scalp reduction procedure, where a $14 \mathrm{~cm} \times 3.5 \mathrm{~cm}$ scarred area of scalp was excised. Three months later, tofacitinib $2.5 \mathrm{mg}$ sublingually was added to the treatment regimen. After a further 12 months of combination therapy there was no improvement in her condition and thus tofacitinib was ceased.

Secukinumab is a human monoclonal antibody which selectively binds to interleukin-17A (IL-17A) and inhibits its interaction with the IL-17 receptor $^{1}$. It has been approved for use in moderate to severe plaque psoriasis, psoriatic arthritis and ankylosing spondylitis ${ }^{1}$. 
Secukinumab subcutaneous injections were acquired through compassionate supply from the manufacturer in this case. Screening investigations performed prior to commencement of secukinumab, including viral hepatitis serology and Quantiferon-TB Gold, were negative.

Figure 1 illustrates the lesion prior to secukinumab therapy. Secukinumab $300 \mathrm{mg}$ was administered subcutaneously at weeks $0,1,2,3$ and 4 followed by 300mg every 4 weeks thereafter. This is the recommended dosing regimen for plaque psoriasis ${ }^{1}$. After 2 months of treatment there was some clinical improvement and cyclosporin was ceased. After 4 months of treatment there was significant improvement in her condition with a reduction in active folliculitis decalvans (Figure 2). Treatment with 4-weekly injections was continued with a sustained response after 7 months. There were no adverse effects.

Folliculitis decalvans is a scarring alopecia which often begins with a patch of hair loss on the vertex scalp with pustules, crusts and tufted hairs ${ }^{2}$. It may affect both males and females. The onset of symptoms before the age of 25 years and the presence of pustules in the alopecic patch are associated with more advanced disease ${ }^{2}$. Conventional treatments include antibiotics, corticosteroids and isotretinoin. Successful treatment of folliculitis decalvans with biologic therapy using the tumour necrosis factor-alpha (TNF- $\alpha$ ) inhibitor adalimumab has previously been described in case reports ${ }^{3,4}$. This case report demonstrates that secukinumab may be a potential treatment option for treatment-refractory folliculitis decalvans, although larger studies are needed to support this theory.

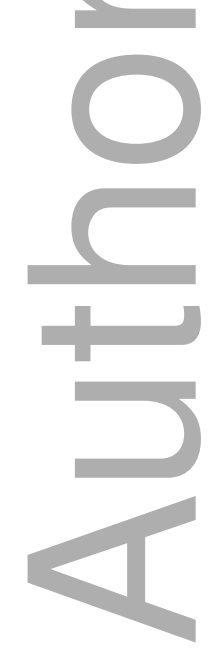

\section{REFERENCES:}

1. Cosentyx.com [homepage on the Internet]. Basel: Novartis Pharmaceuticals Corporation; c2019 [cited 2019 Jul 4]. Available from: 
https://www.pharma.us.novartis.com/sites/www.pharma.us.novartis.com/files/cosenty x.pdf.

2. Vano-Galvan S, Molina-Ruiz A, Fernandez-Crehuet P et al. Folliculitis decalvans: a multicentre review of 82 patients. J Am Acad Dermatol. 2015 May; 72(5 Suppl 1):AB113-AB113.

3. Shireen F, Sudhakar A. A case of isotretinoin therapy-refractory folliculitis decalvans treated successfully with Biosimilar Adalimumab (Exemptia). Int J Trichology. 2018 Sept-Oct;10(5):240-241.

4. Kreutzer K, Effendy I. Therapy-resistant folliculitis decalvans and lichen planopilaris successfully treated with adalimumab. J Dtsch Dermatol Ges. 2014 Jan;12(1):74-76.

\section{FIGURE LEGEND:}

Figure 1: Scalp lesion prior to secukinumab therapy

Figure 2: Scalp lesion after 4 months of treatment with secukinumab

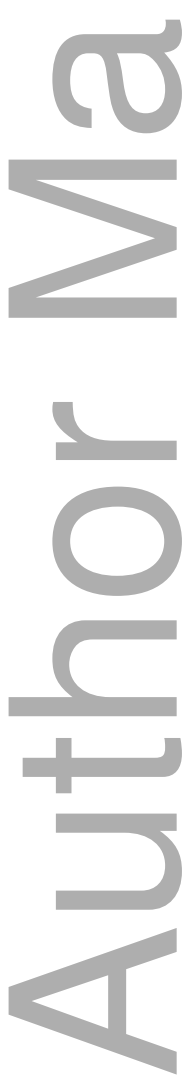



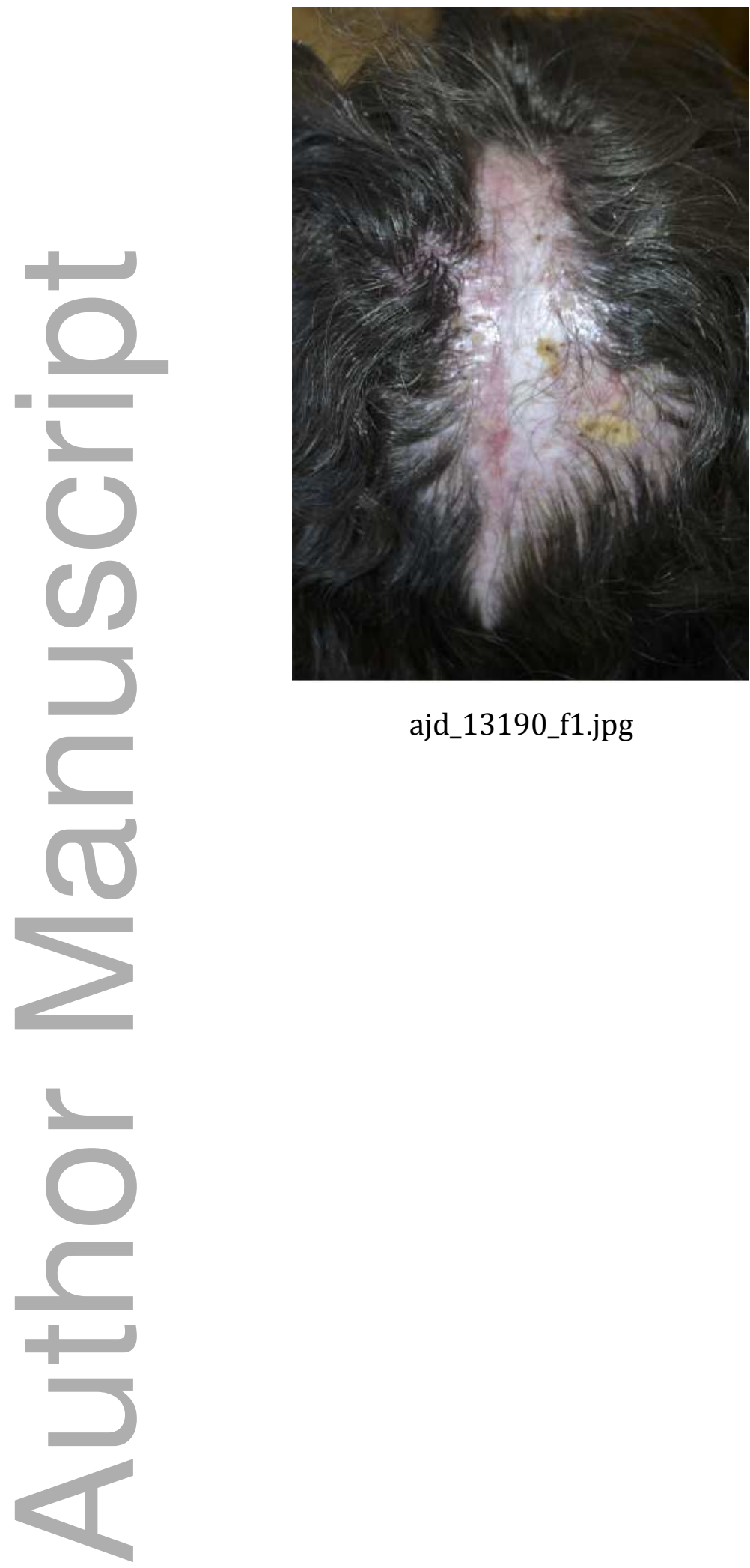

ajd_13190_f1.jpg 


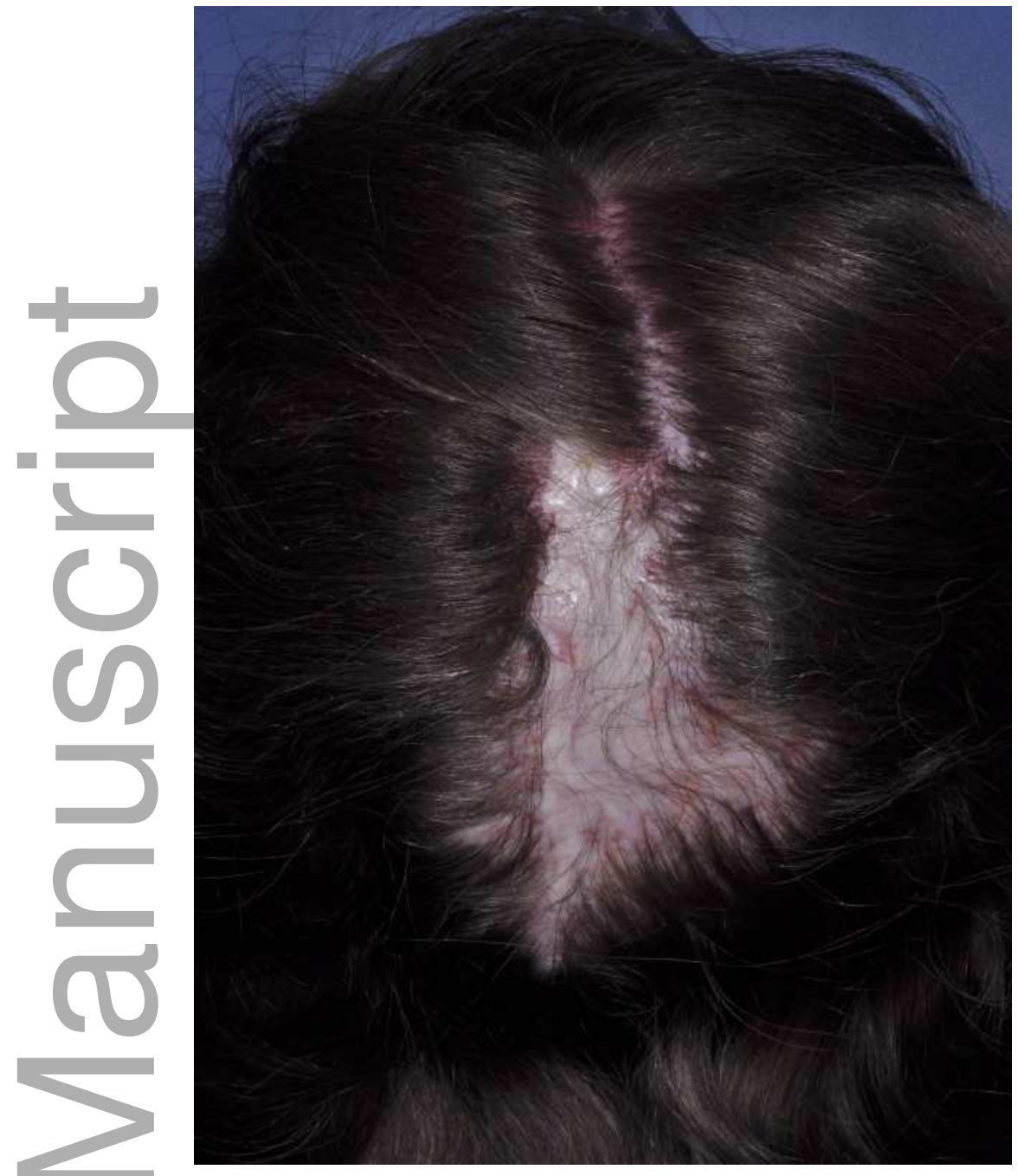

ajd_13190_f2.jpg

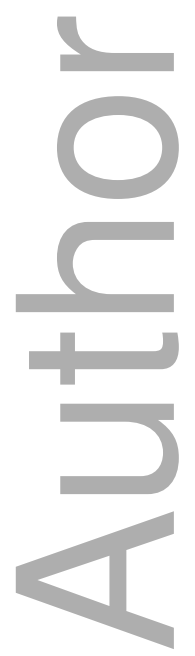




\section{University Library}

\section{- M M N E R VA A gateway to Melbourne's research publications}

Minerva Access is the Institutional Repository of The University of Melbourne

Author/s:

Ismail, FF;Sinclair, R

Title:

Successful treatment of refractory folliculitis decalvans with secukinumab

Date:

2019-10-24

Citation:

Ismail, F. F. \& Sinclair, R. (2019). Successful treatment of refractory folliculitis decalvans with secukinumab. AUSTRALASIAN JOURNAL OF DERMATOLOGY, 61 (2), pp.165-166. https:// doi.org/10.1111/ajd.13190.

Persistent Link:

http://hdl.handle.net/11343/286538 